\title{
Redes de suministro: evaluación del desempeño logístico de los miembros clave en la distribución física de productos acabados
}

\author{
Supply networks: evaluation of the key-members' \\ logistic performance in the physical distribution of \\ finished products
}

Vitoria Lazzarin ${ }^{1}$

Joao Eduardo Azevedo Ramos Silva ${ }^{2}$ Maria Fernanda Ramos ${ }^{3}$

Jose Geraldo Vidal Vieira ${ }^{4}$
${ }^{1}$ Universidade Federal de São Carlos (UFSCar) - CCGT Graduada em Engenharia de Produção vitorialazzarin@gmail.com Sorocaba - SP

${ }^{2}$ Universidade Federal de São Carlos (UFSCar) - CCGT Doutor em Engenharia de Produção pela UFSCar - PPGEP Professor Adjunto do Departamento de Engenharia de Produção jesilva@ufscar.br Sorocaba - SP

${ }^{3}$ Universidade Federal de São Carlos (UFSCar) - CCGT Mestre em Engenharia de Produção pela UFSCar - PPGEP-So mf_ramos91@hotmail.com Sorocaba - SP

${ }^{4}$ Universidade Federal de São Carlos (UFSCar) - CCGT Doutor em Engenharia pela USP - Poli Professor Associado do Departamento de Engenharia de Produção jose-vidal@ufscar.br Sorocaba - SP

Autor correspondente 780, Sorocaba-SP/Brasil - UFSCar/CCGT - Sala 1127

\begin{abstract}
Resumen
En el presente artículo se analiza la relación entre los tres actores principales presentes en la distribución física de los productos finales desde la perspectiva de las redes de suministro: operadores logísticos, empresas de transporte y embarcadores. Por medio de una encuesta realizada a tales agentes, informaciones sobre cómo valoran los criterios de desempeño de los servicios ofrecidos y contratados, como el cumplimiento de las entregas sin errores, atención de solicitudes urgentes, averías y pérdida de mercancía fueron recolectadas. Estos criterios fueron analizados desde el punto de vista de cada miembro de la red que contrata o presta el servicio. Se encontró que los criterios más importantes para embarcadores y los transportadores fueron los relacionados a la atención de pedidos urgentes y cumplimiento del programa de entrega, en tanto que para los operadores logísticos la disponibilidad de vehículos y atendimiento en periodo de alta demanda representaron los criterios más significativos.
\end{abstract}

Palabras Clave: Distribución física. Indicadores de desempeño logístico. Operaciones logísticas. Red de suministro.

\section{Summary}

The present article analyzes the relationship between the three main actors present in the physical distribution of final products from the perspective of supply networks: logistics operators, carriers and shippers. Questionnaires were sent to these agents, information was collected on how they value the performance criteria of the services offered and contracted, such as the fulfillment of deliveries without errors, attention to urgent requests, breakdowns and loss of goods. These criteria were analyzed from the point of view of each member of the chain that hires or provides the service. It was found that the most important criteria for shippers and carriers were those related to the attention of urgent orders and fulfillment of the delivery program, while for the logistics operators the availability of vehicles and service in period of high demand represented the most important criteria.

Keywords: Physical distribution. Logistics performance indicators. Logistics operations. Supply chain. 


\section{Introducción}

En una cadena de suministro, las transacciones efectuadas entre las empresas pueden ser concebidas como relaciones cliente-proveedor, en donde es necesario que información y productos/servicios transiten con efectividad entre estos agentes para garantizar que se cumplan los requerimientos del consumidor final (Meng, 2010). Debido a la complejidad que representa controlar el flujo de recursos a través de la cadena, muchas empresas optan por delegar las actividades de carácter logístico a otros actores como lo son operadores logísticos y transportadores (Domingues, Reis, \& Macário, 2015), de esta forma se pueden concentrar en el eje de su negocio. Con el fin de minimizar el riesgo inversión y maximizar su competitividad, las empresas solicitantes de servicios logísticos subcontratado buscan en sus proveedores características específicas con cierto orden de relevancia, que pueden diferir en importancia del de los prestadores de servicios (Gligor \& Esmark, 2015).

De forma general, la evaluación del nivel de servicio relacionado a la distribución física toma como referencia el punto de vista del receptor del servicio, como consta en la encuesta realizada a 400 embarcadores por Martins, Xavier, De Souza Filho, \& Martins (2011), donde seis constructos fueron evaluados (tiempo, seguridad, precio, confiabilidad, relación con el cliente y atención a las necesidades especiales). También desde el punto de vista de los clientes receptores de servicio, Kadłubek \& Jereb (2014) evaluaron 22 indicadores de desempeño en empresas de transporte en Polonia con base en 149 cuestionarios respondidos por clientes. Por otro lado, enfocándose en los servicios ofrecidos por las empresas transportadoras, Blesz, Sellitto, Ferreira, Herrmann, Sell, Ramos, \& Gruginskie (2017) evaluaron tres empresas de transporte de carga, específicamente en cómo la elección del mercado de actuación influye en la adopción de innovación en los servicios prestados por las compañías trasportadoras. De esta forma, llegar a un punto consensual entre lo que se solicita y lo que se ofrece es vital para desarrollar y explorar el potencial del vínculo entre cliente-prestador de servicios logísticos. Así, este artículo tiene el objetivo evaluar la relación entre tres miembros clave que participan en la distribución física de productos terminados en las cadenas de suministro en Brasil (embarcadores, operadores logísticos y transportadores), utilizando indicadores de desempeño capaces de medir los niveles de servicio proporcionados por los proveedores y que constituyen diferenciales competitivos de distribución física.

El procedimiento técnico utilizado en la investigación fue una encuesta aplicada a los tres miembros clave presentados. Por medio de un cuestionario, se estableció el tipo de relación existente entre el receptor y el proveedor del servicio de distribución física. También, se evaluaron los desempeños logísticos solicitado y ofrecido con relación a 13 temas identificados previamente en la 
etapa de revisión de la literatura.

La mayoría de las investigaciones de este carácter analizaron el desempeño de la relación cliente-proveedor desde la perspectiva del proveedor (Liu \& Lyons, 2011), por lo que la principal contribución de esta investigación es proporcionar un análisis de indicadores centrados en el desempeño logístico desde la perspectiva de quienes solicitan y ofrecen el servicio en el entorno Brasileño. El presente artículo se estructura de la siguiente forma: en la sección 2, se hace una contextualización sobre la relación entre embarcador y prestadores de servicios logísticos; en la sección 3 se hace un levantamiento sobre los principales indicadores de desempeño logístico; en la sección 4 se describe la metodología empleada para llevar a cabo la investigación; en la sección 5 se presentan los resultados y finalmente en la sección 6 se exponen las consideraciones finales.

\section{Redes de suministro: la tríada embarcador - operador logístico - transportador}

En el contexto de las redes de suministro, dependiendo de la solución ofrecida por el prestador de servicios logísticos al cliente, se puede diferenciar entre el operador logístico (responsable de la manipulación, almacenamiento, transporte, procesamiento de pedidos y control de inventarios, entre otros) y el transportador (empresa que asume el transporte de un punto a otro de la red, con la externalización de este servicio), siendo el cliente el embarcador (quien despacha la carga) (Moura y Beuren, 2003). Los transportadores pueden tener su propia flota o asociarse con pequeños transportadores individuales para llevar a cabo sus actividades (Yilmaz y Savasaneril, 2012). Según Aguezzoul (2014) la contratación de un operador logístico puede llevar a aumentar la satisfacción del cliente final y a la penetración de mercados internacionales, pues este provee el conocimiento especializado en la gestión de las actividades involucradas en todas las fases de la red de abastecimiento. Aunque las etapas de manipulación y almacenaje no añadan valor al producto final, el tiempo y costo que se reducen al gestionar adecuadamente el movimiento de materiales pueden ser cuantificados al final del proceso (Yeung, Zhou, Yeung, \& Cheng, 2012). Es decir, tener el producto disponible y entregarlo en las condiciones normales de uso dentro del plazo dado a costos razonables añade valor a la reputación de la marca, generando resultados positivos para la empresa.

Las relaciones que se producen entre el cliente y el proveedor de servicios logísticos dentro de una red de suministro pueden ser evaluados desde el punto de vista quienes contratan u ofrecen el servicio (Murphy \& Poist, 2000), por lo tanto, desde la óptica de contratación del servicio, es posible contratar o subcontratar a un proveedor de servicios logísticos, o sea un embarcador puede contratar a un transportador o a un operador logístico, siendo que el operador logístico también puede subcontratar un transportador; en cuanto a la oferta de servicios, se sabe que el transportador le 
presta servicios tanto al operador logístico como al embarcador y el operador logístico ofrece sus servicios al embarcador (Tezuka, 2011). Cuando el embarcador contrata directamente al transportador, queda bajo el cuidado de uno de ellos las actividades de almacenamiento y gestión de inventario.

Cuando el embarcador selecciona a una empresa para llevar a cabo los servicios de transporte y almacenamiento (transportador u operador logístico), éstos son evaluados según una serie de criterios operativos. Muchos criterios están relacionados al desempeño logístico como la puntualidad, disponibilidad de vehículos, ocurrencia de pérdidas y extravíos y participación relativa en los costos (Zhang \& Tan, 2012). Estos indicadores son ejemplos de métricas de operación importantes que componen la red de suministro que se pretende evaluar en esta investigación. Conforme a lo presentado por Tian, Ellinger y Chen, (2010) la variedad de los servicios prestados por el mismo proveedor, la disponibilidad de información y el desarrollo constante de buenas prácticas también son criterios importantes en la evaluación de un proveedor/cliente cuando se observa desde una perspectiva estratégica.

\section{Indicadores de desempeño logístico}

De acuerdo con Devlin y Yee (2005), en los países en desarrollo, en donde se busca desenvolver un sistema de distribución confiable, es necesario desarrollar prácticas que permitan a las empresas disminuir costos, aumentar el volumen de bienes comercializados, crear economías de escala y aumentar en alcance de actividades de distribución y producción con el fin de mantener su competitividad en el mercado. Para garantizar la efectividad de estas prácticas, el desempeño de las transacciones realizadas entre empresas puede ser controlado mediante indicadores que guíen la adopción de medidas de mejora continua de las actividades de logística y que consecuentemente generen un mejor nivel de servicio (Selviaridis \& Spring, 2007).

Es de destacar que los agentes anteriores y posteriores de la cadena de suministro poseen criterios diferentes para el control de procesos. La empresa controla sus procesos a través de métricas de productividad que contemplan tiempos de procesos y el control del material. Los clientes, por su parte, miden y controlan el proceso por la calidad del servicio prestado por el proveedor (Axsäter, 2015).

Nóbrega y Pizzolato (2012) acompañaron la aplicación de cinco diferentes indicadores de desempeño logístico (Tabla 1). 
Tabla 1 - Indicadores de desempeño

\begin{tabular}{|l|l|}
\hline \multicolumn{1}{|c|}{ Indicador de Desempeño } & \multicolumn{1}{c|}{ Definición } \\
\hline $\begin{array}{l}\text { On Time Delivery (Porcentaje de } \\
\text { pedidos entregados dentro del } \\
\text { plazo pactado) }\end{array}$ & $\begin{array}{l}\text { Número total de pedidos entregados dentro de la } \\
\text { ventana de atendimiento }\end{array}$ \\
\hline $\begin{array}{l}\text { Left on Board } \\
\text { (Devoluciones) }\end{array}$ & $\begin{array}{l}\text { Cantidad de entregas no recibidas por el cliente, } \\
\text { ocasionando el retorno del camión con la carga } \\
\text { enviada, total o parcial }\end{array}$ \\
\hline $\begin{array}{l}\text { Drop Size } \\
\text { (Tamaño del pedido) }\end{array}$ & $\begin{array}{l}\text { Tamaño del pedido que es enviado al cliente, o la } \\
\text { cantidad total vendida dividida por el número de } \\
\text { entregas realizadas }\end{array}$ \\
\hline $\begin{array}{l}\text { Stockout } \\
\text { (Falta de Producto) }\end{array}$ & $\begin{array}{l}\text { Número de eventos en los cuales el cliente quedó sin } \\
\text { producto en sus estaciones }\end{array}$ \\
\hline Número de órdenes urgentes & $\begin{array}{l}\text { La posibilidad de colocación del pedido en el día para } \\
\text { el mismo día, es decir, una orden urgente }\end{array}$ \\
\hline
\end{tabular}

Fuente: Elaboración propia a partir de la información de Nóbrega y Pizzolato (2012).

El nivel de servicio es un indicador común muy utilizado por las empresas para medir el desempeño logístico. Éste se puede medir, por ejemplo, por la disponibilidad de vehículos, calidad del embalaje entregado al segundo eslabón de la cadena por el operador logístico, el grado de exclusividad de un embarcador con un operador logístico o transportador, entre otros indicadores (Devaraj, Krajewski, \& Wei, 2007). Algunos de estos índices influencian directamente el tiempo y la calidad de la entrega final del producto. Por lo tanto, es posible percibir la relación directa entre los indicadores de desempeño y los objetivos definidos en la planificación estratégica de la operación.

Ya para el cliente, atributos de plazo entrega son criterios importantes, sea este intermedio o final. Por lo tanto, la entrega dentro del plazo pactado, en conformidad con el pedido garantiza la confiabilidad de la entrega y el consecuente nivel de servicio, muchas veces trayendo fidelidad del cliente (Gunasekaran, Patel, \& McGaughey, 2004). Poseer procesos flexibles que garanticen el cumplimiento de demandas específicas, hace que la calidad percibida por el cliente sea considerablemente mayor.

Al analizar el desempeño competitivo en toda la cadena de suministro, desde el primer proveedor hasta el cliente final, Prajogo, Chowdhury, Yeung, y Cheng (2012) sostienen que varias métricas influyen directamente, incluyendo la velocidad de entrega, flexibilidad de volumen y capacidad de producción, distribución y almacenamiento, además de costos logísticos en conjunto. Esto sugiere que la integración de los miembros de la cadena tiene múltiples facetas, y que hay 
muchas competencias que se complementan entre sí para lograr un mayor nivel de desempeño logístico ante el cliente más cercano dentro de la red de suministro.

Relaciones duraderas e integración logística tienen vínculos positivos con métricas relacionadas a la entrega, la flexibilidad y el costo. Tales factores de la relación dentro de la red de suministro pueden ser representados por pedidos en conformidad, calidad del producto/pedido y entregas a tiempo (Prajogo et al., 2012).

Deshpande (2012) sostiene que todos los indicadores operativos tienen sesgo financiero. Por ejemplo, la flexibilidad de atendimiento y orientación al cliente son indicadores de que, aunque sean de naturaleza cualitativa, tienen relación directa con el resultado de la empresa, una vez que estimulan la lealtad del cliente y aportan nuevas ventas de productos y/o servicios, aumentando la rentabilidad del negocio.

Jayaram \& Tan (2010) resaltaron que algunos factores importantes al evaluar y seleccionar un socio logístico (3PL - third-party logistics provider). Entre ellos se encuentran: la entrega a tiempo, respuesta rápida en casos de emergencia o demandas específicas, flexibilidad de respuesta a cambios inesperados de la demanda y pedidos de en conformidad con la calidad. Para los autores estos indicadores son cruciales para el seguimiento y la gestión del desempeño de los enlaces de la red de suministro. Ya Angerhofer y Angelides (2006) tienen un enfoque diferente y afirman que las mejores métricas para evaluar las relaciones entre los agentes de la red de suministro, embarcadores y 3PL (transportadores y operadores logísticos) son aquellas que reducen y controlan el efecto látigo en la cadena. Por lo tanto, la utilización de capacidad, la exactitud de la demanda, el nivel de alineación, la calidad del producto, la capacidad de producción, falta de producto, y plazo de comercialización son algunos de los más representativos. La Tabla 2 resume los indicadores de desempeño logístico encontrados en la literatura y que servirán de base para proponer un conjunto de criterios que ayudarán a evaluar el desempeño logístico de los miembros clave de la cadena de suministros en la distribución física de productos acabados. 
Tabla 2 - Resumen de indicadores encontrados en la literatura

\begin{tabular}{|c|c|}
\hline Autor & 010 \\
\hline $\begin{array}{lll}\text { Silva y } & \text { Pizzolato } \\
(2012) & \\
\end{array}$ & Tiempo medio de embarque; Unidades expedidas/hora \\
\hline $\begin{array}{l}\text { Conceição y Quintão } \\
\text { (2004) }\end{array}$ & $\begin{array}{l}\text { Costo del pedido; rotación de inventario; costos de ruptura; } \\
\text { Productos dañados }\end{array}$ \\
\hline $\begin{array}{l}\text { Nóbrega y Pizzolato } \\
\text { (2012) }\end{array}$ & $\begin{array}{l}\text { Porcentaje de pedidos entregados dentro del plazo pactado; } \\
\text { devoluciones; tamaño del pedido; falta del producto; número de } \\
\text { pedidos urgentes }\end{array}$ \\
\hline $\begin{array}{l}\text { Krajewski y } \\
07)\end{array}$ & $\begin{array}{l}\begin{array}{l}\text { Disponibilidad de vehículos; calidad de embalaje; grado de } \\
\text { exclusividad }\end{array} \\
\end{array}$ \\
\hline $\begin{array}{l}\text { Gunasekaran, Patel y } \\
\text { McGaughey(2004) }\end{array}$ & $\begin{array}{l}\text { dentro del plazo; conformidad con el pedido; tasa de } \\
\text { iento de pedidos }\end{array}$ \\
\hline et al. (2012) & $\begin{array}{l}\text { Velocidad de entrega; flexibilidad de volumen; capacidad; costos } \\
\text { logísticos }\end{array}$ \\
\hline \& Tan (2010) & $\begin{array}{l}\text { Porcentaje de pedidos entregados dentro del plazo; respuesta rápida } \\
\text { en casos de emergencia, flexibilidad ante cambios en la demanda; } \\
\text { pedidos en conformidad }\end{array}$ \\
\hline fer & to. \\
\hline
\end{tabular}

Fuente: Elaboración propia.

\section{Metodología}

Esta investigación es de naturaleza aplicada y, de acuerdo con su objetivo, puede ser enmarcada como descriptiva, ya que pretende caracterizar la relación entre los tres actores logísticos participantes de la distribución de productos. De acuerdo al procedimiento técnico que se empleó, se trata de una encuesta.

La metodología para la conducción de la investigación inició por la revisión de la literatura sobre los procesos de distribución física y los procesos logísticos realizados por los miembros clave, sus principales variables y la influencia ejercida en el ciclo completo de transporte. Los indicadores de desempeño logístico recurrentes encontrados en los trabajos seleccionados en la etapa de la revisión de la literatura fueron agrupados en criterios, conforme similitud. Como resultado, se obtuvo una lista de criterios, posteriormente tratados por medio de cuestionarios con el fin de entender las relaciones entre los miembros clave seleccionados. La lista de criterios se presenta en la Tabla 3. 
Tabla 3 - Criterios para evaluación del desempeño logístico de las empresas seleccionadas como miembros clave

\begin{tabular}{l|l}
\multicolumn{1}{c|}{ Indicador de desempeño logístico } & \multicolumn{1}{c}{ Criterios } \\
\hline Tiempo medio de embarque, unidades expedidas/hora & Cumplimiento de ventanas de tiempo \\
\hline Entregas dentro del plazo & Entregas en la fecha acordada \\
\hline Velocidad de entrega, entregas dentro del plazo & Cumplimiento de la agenda de entrega \\
\hline $\begin{array}{l}\text { Conformidad con el pedido, pedidos en conformidad, } \\
\text { tamaño del pedido, tasa de cumplimiento de pedidos }\end{array}$ & Entregas sin error \\
\hline $\begin{array}{l}\text { Respuesta rápida en casos de emergencia, número de } \\
\text { pedidos urgentes, costos de ruptura, grado de } \\
\text { exclusividad }\end{array}$ & Atendimiento de solicitudes urgentes \\
\hline $\begin{array}{l}\text { Productos dañados, calidad de embalaje, costo del } \\
\text { pedido }\end{array}$ & Averías/Extravíos \\
\hline Falta del producto & Robos \\
\hline Devoluciones & Pedidos devueltos \\
\hline Disponibilidad de vehículos & Disponibilidad de vehículos \\
\hline $\begin{array}{l}\text { Flexibilidad de volumen, flexibilidad ante cambios en la } \\
\text { demanda }\end{array}$ & Atendimiento de solicitudes en \\
\hline Costos logísticos, capacidad & períodos de demanda alta \\
\hline $\begin{array}{l}\text { Calidad de embalaje } \\
\text { Velocidad de entrega, rotación de inventario, tiempo } \\
\text { medio de embarque, unidades expedidas/hora, } \\
\text { entregas dentro del plazo, tasa de cumplimiento de } \\
\text { pedidos }\end{array}$ & Ruteo con menor distancia recorrida \\
\hline
\end{tabular}

Fuente: Elaboración propia.

La selección de los criterios fue sustentada en el desarrollo de tres cuestionarios que se aplicaron a los profesionales del área de logística conforme su actuación en la red de suministro (transportadores, operadores logísticos o embarcadores), en las operaciones que involucran la distribución física de productos terminados a locales minoristas en Brasil. Cada cuestionario contenía 3 bloques:

En el bloque 1, el respondiente caracterizaba a la empresa cliente o proveedora según los servicios que prestaba, así como el origen de su capital, nacional o no. Cabe aclarar que el embarcador siempre era un cliente, el transportador siempre un proveedor de servicio logístico y, por fin, el operador logístico que podría ser un cliente o un proveedor de servicio logístico. En este caso, si el par fuese un embarcador el operador sería un proveedor, si el par fuera un transportador, el operador sería un cliente del servicio logístico.

En el bloque 2, el encuestado calificó la relación existente a través de variables como el grado de exclusividad, duración de la relación entre ellos, la localización de la matriz y de la 
región de mayor actuación, la frecuencia de las reuniones y entrenamiento logístico, entre otros.

El tercer bloque se refiere al desempeño logístico entre cliente y proveedor. En este bloque se utilizó la escala de 0 a 10, donde 10 es el mejor resultado, para cada tema presentado en la Tabla 3. Esta escala fue fácil de entender y respuestas rápidas por los encuestados.

Inicialmente el cuestionario fue aplicado de forma directa a los encuestados conforme su disponibilidad y de los investigadores. Sin embargo, para aumentar el alcance de los cuestionarios, hubo casos en que éstos fueron enviados por correo electrónico, mientras que otros fueron respondidos a través de la plataforma electrónica de SurveyMonkey.

Posteriormente fue elaborado un análisis cuantitativo de los datos recolectados. A partir de los datos de los cuestionarios fueron obtenidos índices basados en la estadística descriptiva: media, moda y desviación estándar, para la mejor comprensión de las variables.

La aplicación de los cuestionarios se produjo entre enero y diciembre de 2012 a aquellos profesionales que ejercían, preferentemente, puestos de dirección, gerencia, coordinación y supervisión dentro de las empresas caracterizadas como embarcadores, transportadores y operadores logísticos. El universo de contactos fue de 2.200 profesionales de una lista de empresas de las que se obtuvieron 139 retornos, lo que representa una tasa de respuesta del 6,3\%.

Con el fin de conocer si la muestra era representativa o no, se calculó el tamaño de muestra necesaria para inferir sobre los indicadores más importantes en la relación entre los miembros de la red de suministro. Para este propósito, se utilizó la fórmula:

$$
n=\left(Z_{\frac{2}{2}} * \partial\right) / E
$$

Donde $Z_{\frac{\alpha}{2}}$ es el valor crítico que corresponde al intervalo de confianza deseado (95\%); $\partial$ es la desviación estándar de la variable estudiada, en el caso de este estudio "cumplimiento de la agenda de entrega"; $E$ es que el margen de error entre la media de la muestra y la media de la población; finalmente, $n$ es el tamaño de la muestra. Como premisa, fue utilizado el criterio ya mencionado para los embarcadores, una vez que este representa la mayor cantidad de cuestionarios. Para el nivel de confianza del $95 \%$ hay un $\alpha$ asociado de 0,1 con $Z_{\frac{\alpha}{2}}$ de 1,96 , encontrado previamente por estadística.

El perfil de los encuestados indica un promedio de 8 años de experiencia en el cargo, con edad entre los 21 y 64 años. Las principales características de la muestra son presentadas en la Tabla 4. De 
acuerdo con la información allí consignada, la categoría de empresa con la mayor tasa de respuesta fue "operador logístico", que representa alrededor del $40 \%$ del total de los cuestionarios contestados, seguido por los transportadores (34\%) y, finalmente, los embarcadores. Esto se debió a que la lista de contactos contenía una mayor cantidad funcionarios de operadores logísticos que, por sugerencia, indicaron transportadores como público objetivo de la investigación. Es de destacar que hubo casos en que los miembros de la misma empresa respondieron más de un cuestionario, entretanto, evaluando socios diferentes, asegurando así la realización de una única evaluación por empresa.

Tabla 4 - Característica de los entrevistados y de las empresas

\begin{tabular}{|c|c|c|c|}
\hline Variable & Categorías & $\begin{array}{l}\text { Frecuencia } \\
\text { (Cantidad) }\end{array}$ & $\begin{array}{l}\text { Porcentaje en la } \\
\text { muestra (\%) }\end{array}$ \\
\hline \multirow{3}{*}{$\begin{array}{l}\text { Tipo de Empresa } \\
\text { respondiente }\end{array}$} & Operador Logístico & 79 & 38 \\
\hline & Transportador & 65 & 34 \\
\hline & Embarcador & 88 & 28 \\
\hline \multirow{5}{*}{$\begin{array}{l}\text { Facturación Anual } \\
\text { (R\$) }\end{array}$} & $<16.000 .000$ & 41 & 17,7 \\
\hline & $16.000 .000-90.000 .000$ & 27 & 11,6 \\
\hline & $90.000 .000-300.000 .000$ & 19 & 8,2 \\
\hline & $>300.000 .000$ & 33 & 14,2 \\
\hline & En blanco & 112 & 48,3 \\
\hline \multirow{7}{*}{ Cargo } & Director & 28 & 12 \\
\hline & Gerente & 51 & 22 \\
\hline & Supervisor & 21 & 9 \\
\hline & Coordinador & 23 & 10 \\
\hline & Analista & 18 & 7,7 \\
\hline & Otros & 22 & 9,5 \\
\hline & En blanco & 69 & 29,7 \\
\hline
\end{tabular}

Fuente: Elaboración propia.

En la Tabla 4 también puede observarse que la muestra comprende en su mayoría encuestados de alta o media dirección de la empresa (directores, gerentes y supervisores), lo que representa el $43 \%$ del total de respuestas obtenidas con identificación del entrevistado.

También se encontró que en términos de facturación anual, de las respuestas obtenidas, se produjo una mayor concentración de respuestas en las categorías "ventas menores a 16 millones" $(17,7 \%)$. También se encontró que en promedio, el $67 \%$ de las empresas que respondieron son de capital nacional.

En los sectores de actuación más representativa, se observó una similitud entre los cuestionarios respondidos. El sector más representativo entre los embarcadores (27,3\% y 21,6\%), operadores logísticos $(51,9 \%$ y $50,6 \%)$ y los transportadores $(38,5 \%$ y $36,9 \%)$ fue "consumo/al por menor" seguido de "automoción/piezas de automóviles ", respectivamente. 
En el caso estudiado, la región de actuación con el mayor número de socios comerciales, sean estos embarcadores, transportadores u operadores logísticos, es el estado de São Paulo, con alrededor del 50\% de las empresas. La región brasileña centro-este compuesta por Río de Janeiro, Minas Gerais y Espírito Santo es la segunda con el mayor número de empresas dedicadas a la logística, con el $41 \%$ de todos los cuestionarios respondidos. Estos datos tienen el sesgo de que las empresas que formaron parte de la investigación son en gran parte del estado de São Paulo.

Después de la aplicación de los cuestionarios a los representantes de las empresas, los datos se procesaron y la información fue analizada para entender cómo se produce la distribución física de los productos terminados en las redes de suministro. El tratamiento de los datos se llevó a cabo en IBM SPSS 22.0 con la ayuda de Office Excel del paquete de Office 2010

\section{Resultados}

A continuación, se presentan los tipos más importantes de operación para cada eslabón de la cadena de suministro, siendo evaluada siempre la relación entre agentes de dos en dos. Cabe agregar que en algunos casos se presentó la ocurrencia de triangulación entre los miembros clave en los que un mismo transportador, un operador logístico y un embarcador se evaluaron mutuamente. En la ilustración 1, consta el tipo de operación contratante del embarcador con el operador logístico y con el transportador

Ilustración 1 - Actividades más importantes en las relaciones con embarcadores

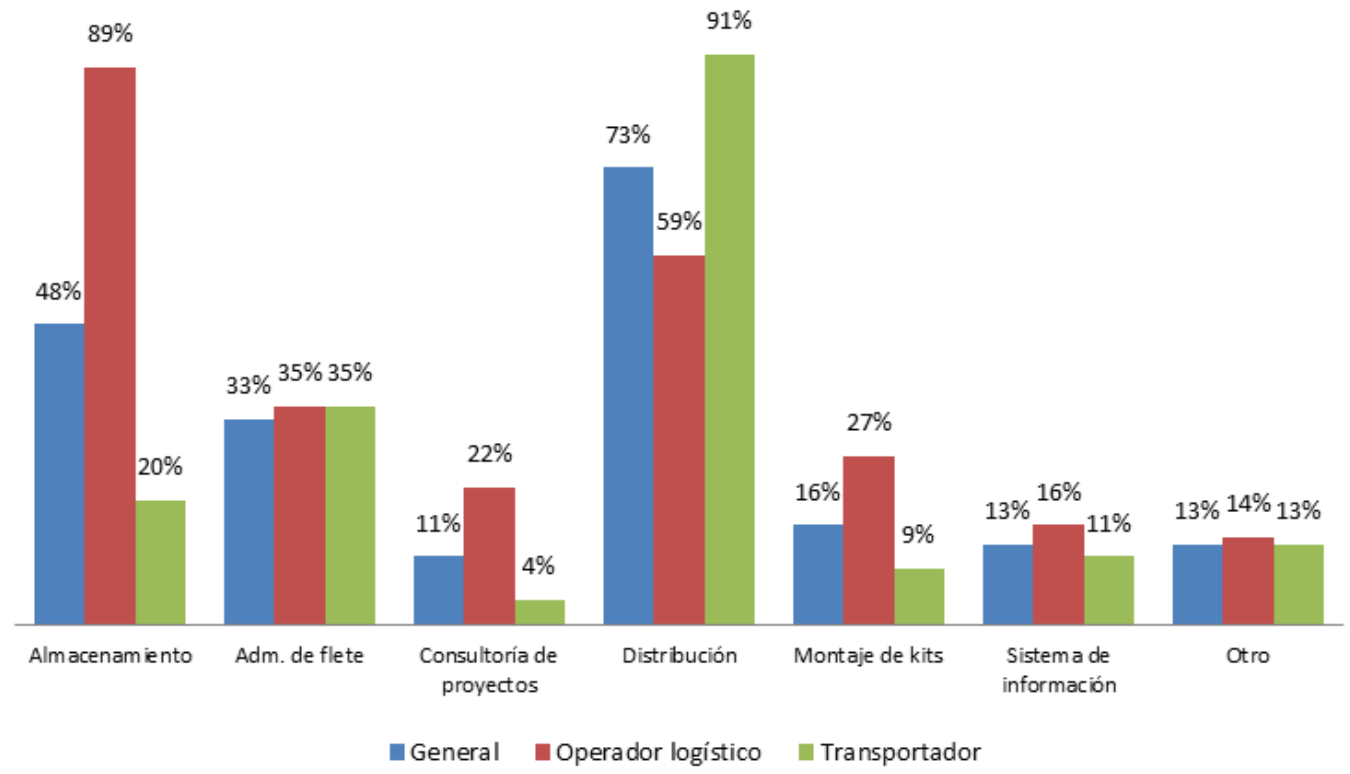

Fuente: Elaboración propia. 
Se puede analizar que, cuando se trata del embarcador, el servicio de mayor contratación es el de distribución (73\%), es decir, la operación de transporte, seguida del servicio de almacenamiento (48\%). Esto se debe a la necesidad de subcontratar el transporte de los productos, ya que es una actividad que no añade valor al producto (Moura \& Beuren, 2003), siendo necesario reducir los costos involucrados en el proceso. Es de destacar que entre las opciones, había la posibilidad de marcar más de un servicio contratado, no siendo obligatorio sumar $100 \%$ en cada una de las actividades.

Por la misma razón de no añadir valor al producto, los embarcadores contratan los servicios de almacenamiento de los operadores logísticos, hecho observable en la ilustración 1 con el 89\% de los servicios contratados, dado que en la mayoría de las empresas es necesario disponer de espacio para la ubicación de productos. Al analizar los datos obtenidos, en el caso de los operadores logísticos, la diversidad de servicios ofrecidos es mayor que la de los transportadores, enfocados mayoritariamente en la operación de distribución. Se observa que, con excepción de la operación de distribución, para todas las demás actividades el porcentaje indicado para los operadores logísticos es mayor justamente por su mayor diversidad de servicios. En la ilustración 2, se comparan los servicios contratados y ofrecidos por los operadores logísticos a los embarcadores y transportadores.

Ilustración 2 - Actividades más importantes en las relaciones con embarcadores

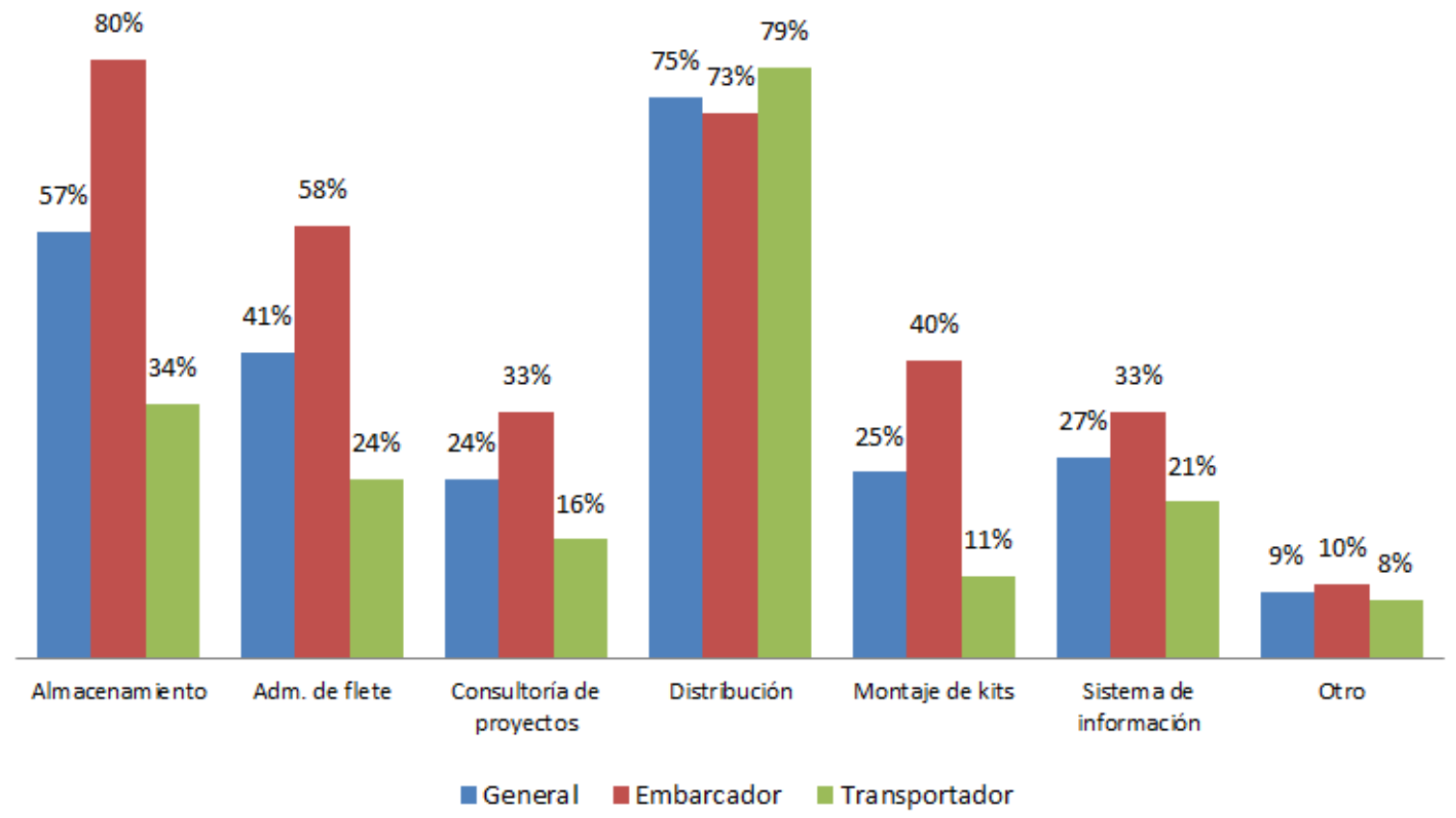

Fuente: Elaboración propia.

Demostrado por los datos, la relación entre los operadores logísticos y transportadores se 
vuelca principalmente a la distribución, con un 79\%. Esto pues, en muchas ocasiones, los operadores logísticos no cuentan con equipos de transporte propio o que estén acondicionados para movilizar carga bajo condiciones especiales, en vez de eso, se asocian con transportadores que proveen el equipo necesario para transportar sus cargas (Ülkü \& Bookbinder, 2012). Un ejemplo de transporte que requiere un servicio específico por parte del operador logístico, y que este puede subcontratar a una transportadora, son las cargas refrigeradas que requieren equipos y vehículos que conserven la inocuidad de los alimentos.

En la relación entre el operador logístico y el embarcador, el almacenamiento y la distribución son los principales servicios ofrecidos, con un $80 \%$ y $73 \%$, respectivamente, sin limitarse a estos, sino que se extiende a servicios de la gestión de transporte de mercancías, sistema de información y de montaje kits. En la relación entre el operador logístico y el embarcador, se observa un aumento de la demanda para el servicio de almacenamiento, con el $80 \%$ de los cuestionarios respondidos. Esto ocurre por la necesidad de disponer de espacio para el almacenamiento de los productos acabados. Una vez que el espacio en las empresas es un elemento de alto costo, la externalización es necesaria.

Al evaluar la ilustración 3, que muestra la relación de servicios del transportador con el operador logístico o embarcador, es notable que la distribución de los productos es el servicio que se ofrece con mayor frecuencia con valores por encima del $80 \%$ en todos los casos. De hecho, al analizar los resultados, fue comprobado que las empresas transportadoras poseen la distribución como su actividad principal, la cual posee especialización y permite atender incluso a los operadores logísticos de una manera diferenciada, principalmente cuando hay especificidad de las cargas, por ejemplo, cargas fuera del padrón, cargas refrigeradas o que requieren seguridad adicional. Cabe mencionar que existen transportadores que también ofrecen servicio de almacenamiento, con un $50 \%$ de respuestas, lo que demuestra la necesidad de añadir servicios a aquellos ya existentes. 
Ilustración 3 - Actividades más importantes en las relaciones con transportadores

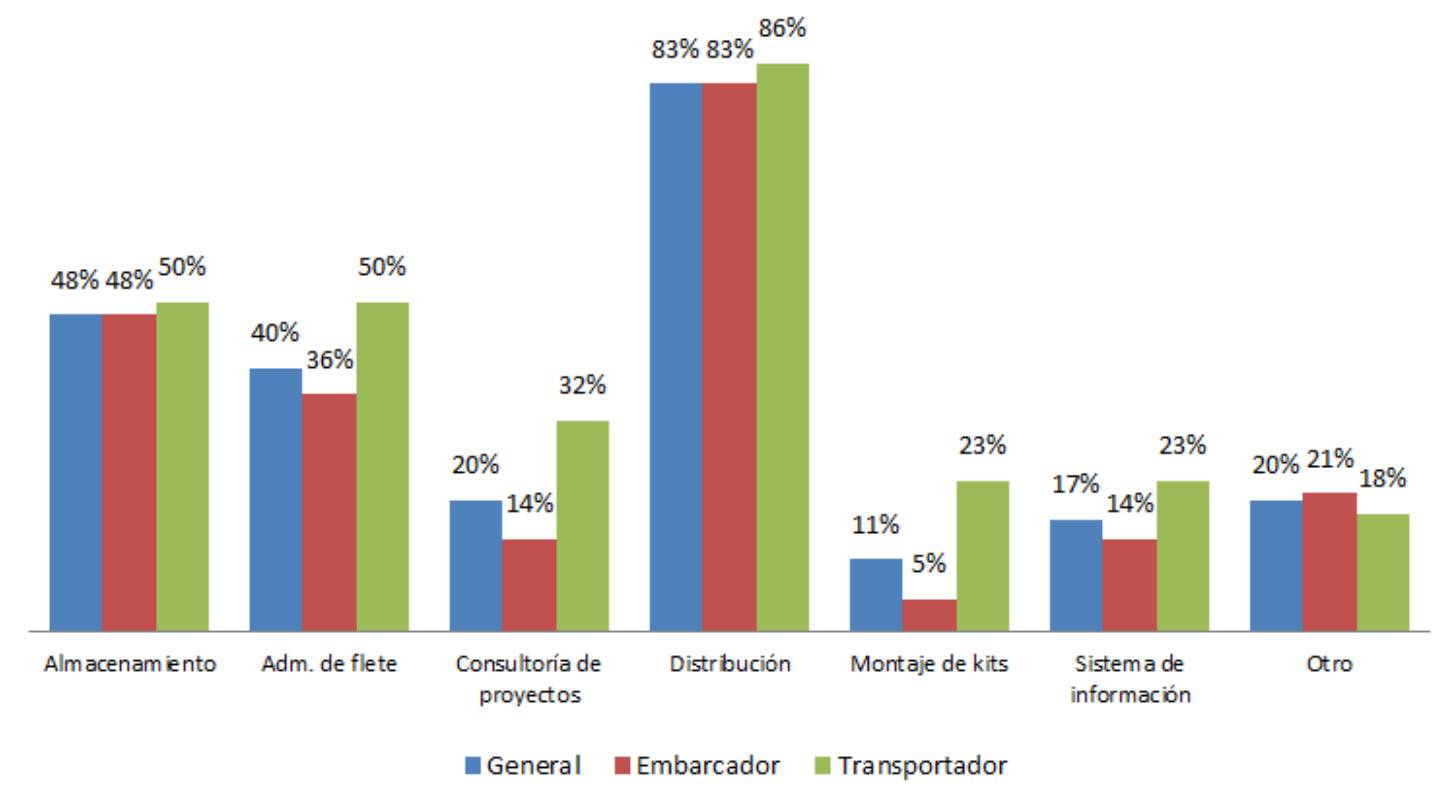

Fuente: Elaboración propia.

Un análisis interesante es la comparación de las puntuaciones con respecto a la oferta y demanda de servicios. Con este fin, la Tabla 5 muestra las notas dadas por el cliente al proveedor (contratación de servicios) y en la Tabla 6 se muestran las notas dadas al cliente por el proveedor (oferta de servicios). 
Tabla 5 - Puntuaciones de desempeño entre las relaciones de contratación de servicio

\begin{tabular}{|c|c|c|c|c|c|c|}
\hline \multirow{2}{*}{ Criterio } & \multicolumn{2}{|c|}{$\begin{array}{l}\text { Embarcador } \times \text { Op. } \\
\text { Logístico }\end{array}$} & \multicolumn{2}{|c|}{$\begin{array}{l}\text { Embarcador } \mathrm{x} \\
\text { Transportador }\end{array}$} & \multicolumn{2}{|c|}{$\begin{array}{l}\text { Op. Logístico x } \\
\text { Transportador }\end{array}$} \\
\hline & Media & \begin{tabular}{|c|} 
Desv. \\
Estándar
\end{tabular} & Media & $\begin{array}{c}\text { Desv. } \\
\text { Estándar }\end{array}$ & Media & $\begin{array}{l}\text { Desv. } \\
\text { Estándar }\end{array}$ \\
\hline Cumplimiento de ventanas de tiempo & 5,0 & 3,7 & 6,3 & 2,9 & 6,3 & 3,3 \\
\hline Entregas en la fecha acordada & 5,6 & 3,6 & 6,8 & 2,9 & 6,2 & 3,4 \\
\hline Cumplimiento de agenda de entrega & 5,5 & 3,8 & 6,8 & 3,0 & 6,2 & 3,5 \\
\hline Entregas sin error & 4,9 & 3,6 & 6,4 & 3,6 & 6,3 & 3,5 \\
\hline Atendimiento de solicitudes urgentes & 5,9 & 3,6 & 7,2 & 3,0 & 6,3 & 3,5 \\
\hline Averías/extravíos & 4,7 & 3,6 & 5,7 & 3,5 & 5,6 & 3,8 \\
\hline Robos & 5,1 & 4,3 & 6,3 & 3,6 & 6,1 & 3,9 \\
\hline Pedidos devueltos & 4,9 & 4,0 & 6,4 & 3,3 & 5,4 & 3,8 \\
\hline Disponibilidad de vehículos & 4,0 & 3,9 & 6,4 & 3,2 & 6,8 & 3,5 \\
\hline $\begin{array}{l}\text { Atendimiento de solicitudes en período } \\
\text { de alta demanda }\end{array}$ & 5,2 & 3,7 & 6,6 & 3,1 & 6,5 & 3,5 \\
\hline Ruteo con menor distancia recorrida & 4,3 & 3,9 & 4,7 & 3,8 & 4,8 & 4,2 \\
\hline Apariencia y limpieza de los vehículos & 3,5 & 4,0 & 5,8 & 3,8 & 6,4 & 4,0 \\
\hline Tiempo de ciclo & 4,3 & 4,0 & 6,4 & 3,3 & 6,1 & 3,7 \\
\hline
\end{tabular}

Fuente: Elaboración propia.

Se observa que las puntuaciones medias de contratación de servicio (Tabla 5) tienen valores entre 5 y 6 , mientras que la puntuación media para la oferta de servicios (Tabla 6) oscila entre 6 y 8 . Un análisis de esta diferencia de puntuación sugiere que los clientes evalúan a sus proveedores de forma más rigurosa con el fin de tornar los servicios mejores, lo que sustenta las notas menores. Entretanto, aquellos que ofrecen el servicio evalúan su desempeño frente a los clientes de manera positiva, con una puntuación más alta. 
Tabla 6 - Puntuaciones de desempeño entre las relaciones de oferta de servicio.

\begin{tabular}{|c|c|c|c|c|c|c|}
\hline \multirow{2}{*}{ Criterio } & \multicolumn{2}{|c|}{$\begin{array}{c}\text { Embarcador } \times \text { Op. } \\
\text { Logístico }\end{array}$} & \multicolumn{2}{|c|}{$\begin{array}{l}\text { Embarcador } \mathrm{x} \\
\text { Transportador }\end{array}$} & \multicolumn{2}{|c|}{$\begin{array}{l}\text { Op. Logístico x } \\
\text { Transportador }\end{array}$} \\
\hline & Media & $\begin{array}{c}\text { Desv. } \\
\text { Estándar }\end{array}$ & Media & $\begin{array}{l}\text { Desv. } \\
\text { Estándar }\end{array}$ & Media & $\begin{array}{l}\text { Desv. } \\
\text { Estándar }\end{array}$ \\
\hline $\begin{array}{l}\text { Cumplimiento de ventanas de } \\
\text { tiempo }\end{array}$ & 7,7 & 3,0 & 7,0 & 3,6 & 7,3 & 2,8 \\
\hline Entregas en la fecha acordada & 7,7 & 3,0 & 6,9 & 3,6 & 7,5 & 3,0 \\
\hline Cumplimiento de agenda de entrega & 7,8 & 3,0 & 7,1 & 3,6 & 7,3 & 3,0 \\
\hline Entregas sin error & 8,0 & 2,8 & 6,5 & 3,6 & 7,1 & 2,9 \\
\hline Atendimiento de solicitudes urgentes & 8,2 & 2,8 & 7,2 & 3,7 & 7,1 & 2,9 \\
\hline Averías/extravíos & 7,7 & 2,9 & 6,0 & 3,7 & 6,0 & 3,7 \\
\hline Robos & 7,8 & 3,5 & 6,8 & 3,5 & 6,5 & 3,9 \\
\hline Pedidos devueltos & 7,6 & 3,5 & 6,7 & 3,5 & 6,3 & 3,7 \\
\hline Disponibilidad de vehículos & 7,3 & 3,4 & 7,2 & 3,6 & 7,7 & 3,2 \\
\hline $\begin{array}{l}\text { Atendimiento de solicitudes en } \\
\text { período de alta demanda }\end{array}$ & 7,4 & 3,2 & 7,0 & 3,6 & 7,4 & 3,1 \\
\hline Ruteo con menor distancia recorrida & 7,1 & 3,9 & 6,8 & 3,7 & 5,9 & 4,0 \\
\hline Apariencia y limpieza de los vehículos & 7,4 & 3,5 & 6,9 & 4,0 & 6,6 & 3,4 \\
\hline Tiempo de ciclo & 7,1 & 3,8 & 6,6 & 4,0 & 7,0 & 3,4 \\
\hline
\end{tabular}

Fuente: Elaboración propia.

Tomando por ejemplo el aspecto "Disponibilidad de vehículos": el embarcador evaluó al operador logístico con nota 4.0 (promedio), sin embargo, bajo el panorama de oferta, el operador logístico le atribuyó nota 7,7 (promedio) al embarcador. Se observa una diferencia de 3,7 puntos entre las dos evaluaciones, es decir, el proveedor evalúa su servicio frente al embarcador de una forma más positiva, atribuyéndole una puntuación más alta, mientras que, a su vez, el embarcador juzgó el servicio prestado con notas menores. El propósito de esta posición es siempre requerir servicios de mayor calidad.

Otro diagnóstico percibido fue entre las propias relaciones de contratación entre embarcador $x$ operador logístico, embarcador $\mathrm{x}$ transportador y operador logístico x transportador, donde se notan puntuaciones más bajas en el caso de la primera relación. Aquello representa una operación de peor calidad por parte del operador logístico hacia el cliente, o entonces una mayor exigencia por parte del embarcador al operador logístico, tornando su relación más conflictiva.

Con las puntuaciones de la tabla oferta de servicios (Tabla 6), se encuentra las medias de puntuación por relación igual a 7,0 (transportador $x$ embarcador); 6,8 (transportador $x$ operador 
logístico) y 6.9 (operador logístico x embarcador). En general, las mayores puntuaciones alcanzadas, que favorecen un buen desempeño logístico fueron "Atendimiento de solicitudes urgentes" con 8.2 en relación transportador x embarcador y 7.2 en la relación transportador x operador logístico y "Disponibilidad de vehículos" con nota de 7.7 la relación entre el embarcador x operador logístico.

Tanto para la contratación como para la oferta de servicio, los criterios de mayor puntuación fueron los mismos, es decir, "Entrega en la fecha acordada", "Atendimiento de solicitudes urgentes" y "Disponibilidad de los vehículos", como se muestra en las Tablas 6 y 7.

Para los criterios de "Tiempo de ciclo" y "Averías/Extravíos", los proveedores de servicios convergen en las menores puntaciones en la Tabla 6, lo que indica que todavía hay mejoras que se deben alcanzar en la calidad de estos servicios. En lo referente a "Tiempo de ciclo", aunque la nota media no fue baja $(7,1)$, los transportadores eligieron este criterio como el más importante en su relación con los embarcadores, por lo que se infiere la necesidad de una mayor atención como este indicador.

Respecto al criterio "Averías/extravíos," este es el criterio en el que las notas son más bajas (puntuaciones de 6.0 en la Tabla 6), también apuntando a la necesidad de una mayor atención por parte de los oferentes de servicios en materia de seguridad y control para minimizar la pérdida de mercancía encaminada al cliente. También es necesaria una manipulación más cuidadosa para evitar que, al llegar al destino, la carga se encuentre con el embalaje dañado o quebrado por los esfuerzos mecánicos.

En la evaluación del transportador, el atendimiento de peticiones urgentes fue reportado como un diferencial tanto para el embarcador y como para el operador logístico, siendo el servicio en que hay mayor atención. Al analizar los motivos que llevaron a este resultado, se estima que esto ocurre por la expectativa de atendimiento en períodos de alta demanda, así como en eventos puntuales durante la prestación del servicio.

Un importante cruce de los datos obtenidos es la verificación de los servicios que se ofrecen a un cliente y aquellos requeridos por él. Por lo tanto, se realizó una comparación de dos en dos clases, que se resume en las ilustraciones 4, 5, y 6 . En las ilustraciones se encuentran los servicios deseados por los embarcadores y los ofrecidos a éstos tanto por los operadores logísticos (ilustración 4) como por los transportadores (ilustración 5), así como los servicios deseados por los operadores logísticos al contratar un transportador (ilustración 6). 
Ilustración 4 - Comparación entre servicios ofrecidos y contratados por los embarcadores a los oper. logísticos.

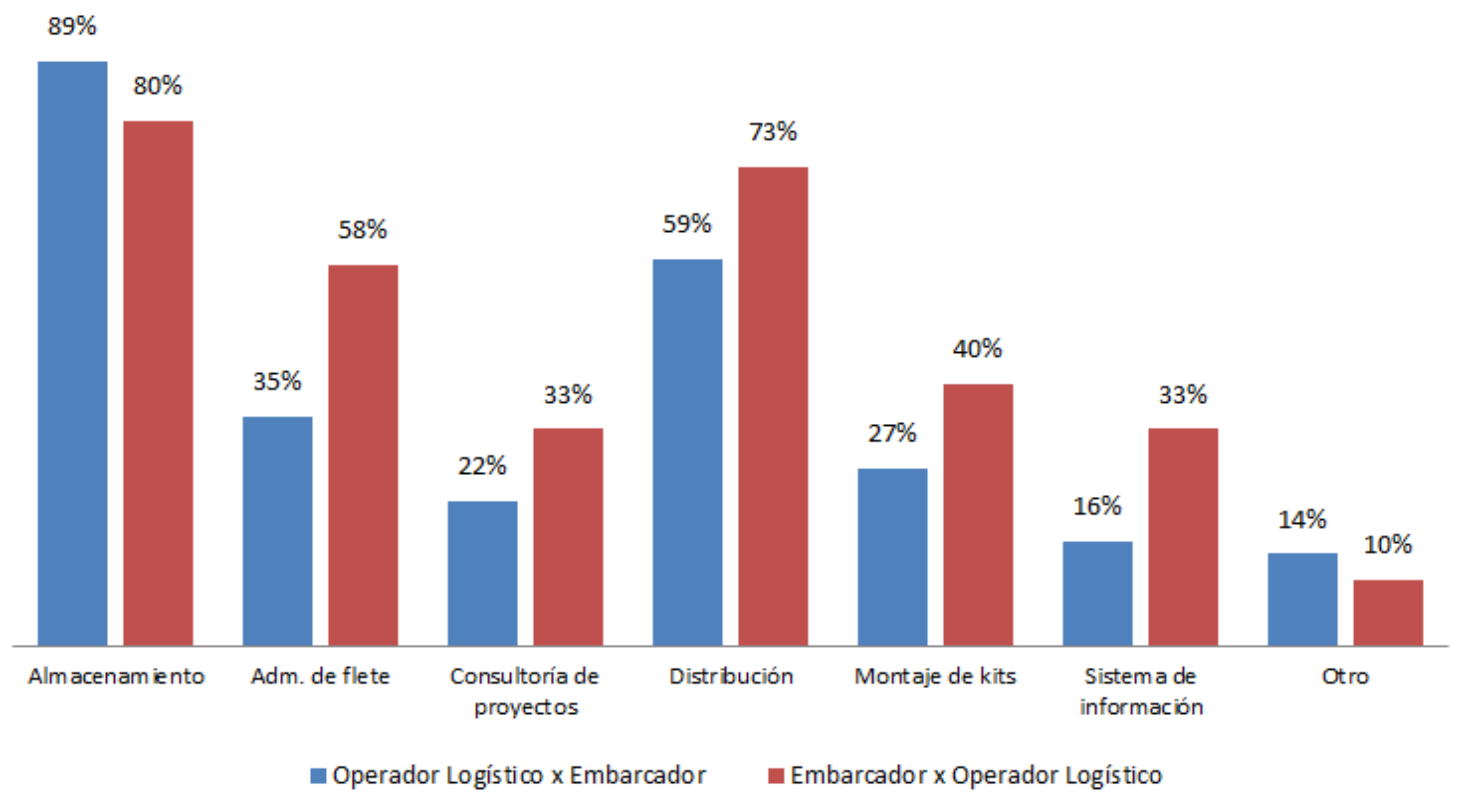

Fuente: Elaboración propia.

La ilustración 4 muestra la comparación entre los servicios deseados por los embarcadores y los que ofrecen los operadores logísticos. Como puede ser observado, los servicios más requeridos por los embarcadores, "distribución", "almacenamiento" y " gestión de transporte de mercancías" con el 80\%, $73 \%$ y $58 \%$, respectivamente, son los servicios que los operadores logísticos más se esfuerzan por ofertar, dado que son los que tienen el mayor porcentaje ( $89 \%$, 59\% y $35 \%$, respectivamente).

La ilustración 5 compara los servicios más deseados por los embarcadores, cuando se refiere a los transportadores, así como los servicios más ofrecidos por los transportadores a los embarcadores. 
Ilustración 5 - Comparación entre servicios ofrecidos y contratados por los embarcadores a los transportadores.

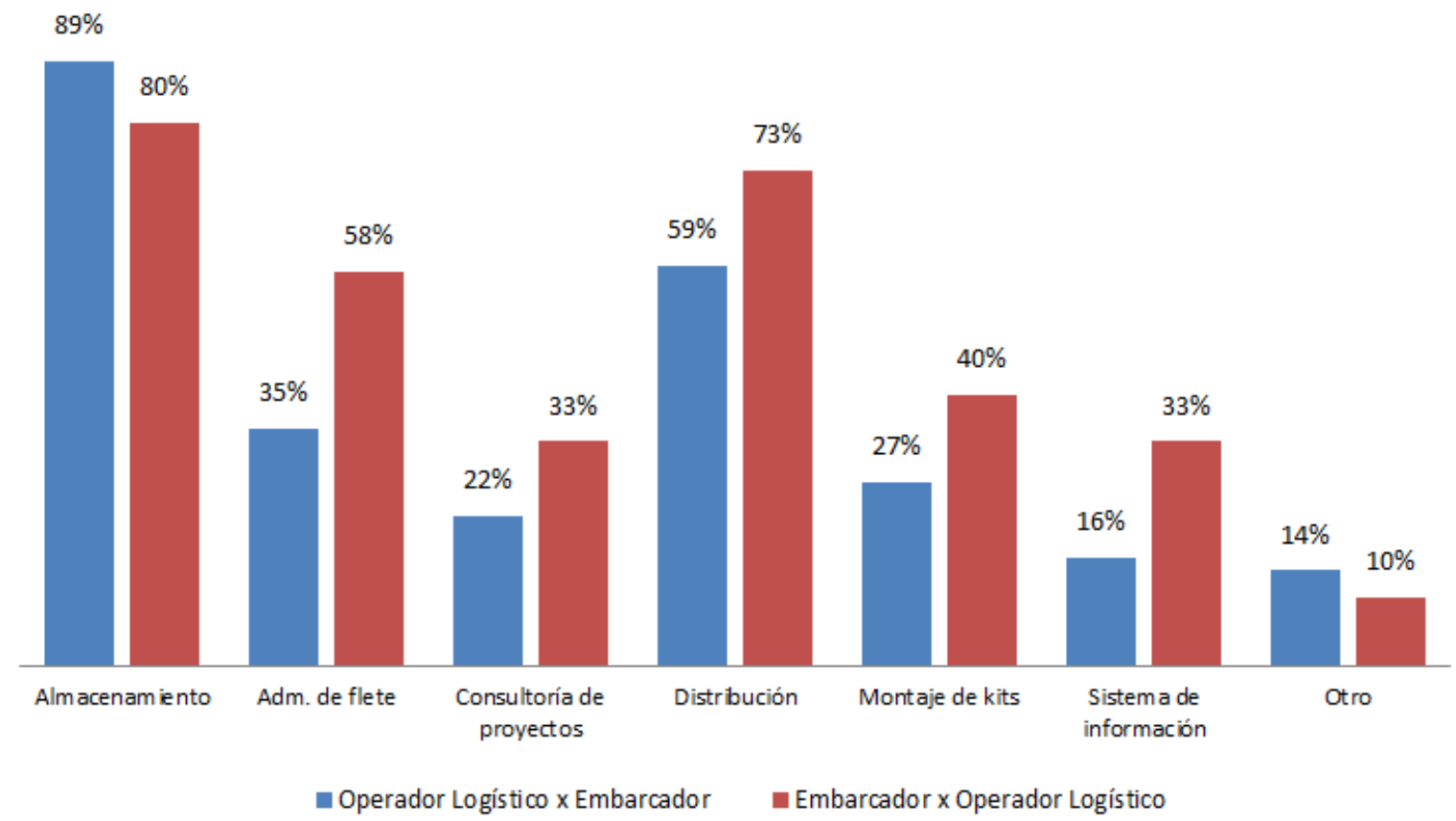

Fuente: Elaboración propia.

Observando los resultados, se concluye que los servicios de "distribución", "almacenamiento" y "gestión de transporte de mercancías" son aquellos en los que el embarcador tiene mayor interés con el $83 \%, 48 \%$ y $36 \%$, respectivamente. Del mismo modo, en lo relacionado a los servicios de "distribución" y " gestión de transporte de mercancías" (91\% y 35\%, respectivamente), el transportador se alinea con los embarcadores, pues considera estos servicios como los más importantes dentro de la empresa. Sin embargo, al analizar el servicio de almacenamiento, se ve una alta demanda por parte de los embarcadores y poca oferta por parte de los transportadores. Se cree que esto ocurre por la dificultad o la competitividad para ejecutar el servicio frente a otros proveedores especializados, como los operadores logísticos.

En la ilustración 7 se explora la relación entre los transportadores y operadores logísticos sobre las posibilidades de servicios entre estos miembros de la cadena de suministro. 
Ilustración 6 - Comparación entre servicios ofrecidos y contratados por los operadores logísticos a los transportadores.

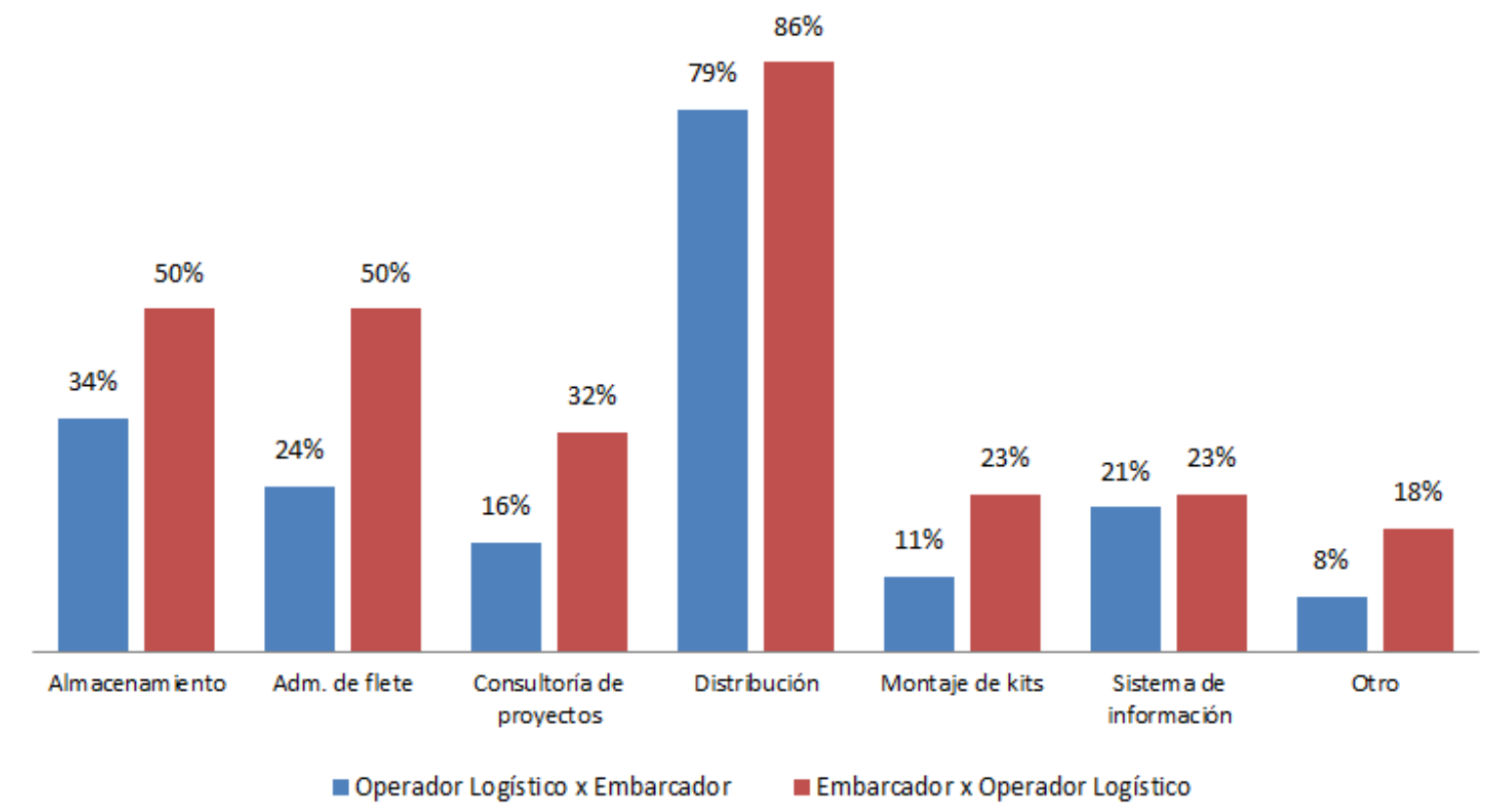

Fuente: Elaboración propia.

Como puede advertirse, los servicios de "distribución", "almacenamiento" y "gestión de transporte de mercancías" son los más representativas en la relación transportador $\mathrm{x}$ operador logístico, con un 79\%, 34\% y 24\%, respectivamente. Sin embargo, el operador logístico cree que el principal servicio proporcionado por el transportador es la distribución (86\%).

Fueron obtenidas las estadísticas de los principales criterios mencionados relacionados al desempeño logístico para los tres miembros clave de la cadena de suministro, evaluados por separado. Las tablas 8, 9 y 10 muestran los resultados de los criterios enumerados en orden decreciente según sus valores promedio en las evaluaciones elaboradas por embarcadores, operadores logísticos y transportadores. 
Tabla 7 - Notas de los criterios evaluados y estadística descriptiva para los embarcadores

\begin{tabular}{|l|l|l|l|l|l|l|l|}
\hline \multicolumn{1}{|c|}{ Criterio } & Mín. & Med. & Máx. & $\begin{array}{c}\text { Desv. } \\
\text { Estand. }\end{array}$ & $\begin{array}{c}\text { 10 } \\
\text { cuartil }\end{array}$ & $\begin{array}{c}\text { 30 } \\
\text { cuartil }\end{array}$ & $\begin{array}{c}\text { Notas encima } \\
\text { de la media }\end{array}$ \\
\hline Atendimiento de solicitudes urgentes & 2 & 6,5 & 10 & 6,0 & 6 & 9 & 60 \\
\hline Cumplimiento de agenda de entrega & 3 & 6,2 & 10 & 3,4 & 5 & 9 & 54 \\
\hline $\begin{array}{l}\text { Atendimiento de solicitudes en período } \\
\text { de alta demanda }\end{array}$ & 3 & 6,0 & 10 & 3,4 & 4 & 9 & 58 \\
\hline Entregas en la fecha acordada & 3 & 5,9 & 10 & 3,5 & 4,3 & 8,8 & 61 \\
\hline Robos & 0 & 5,8 & 10 & 4,0 & 0 & 9 & 53 \\
\hline Pedidos devueltos & 0 & 5,8 & 10 & 3,7 & 2 & 9 & 54 \\
\hline Entregas sin error & 3 & 5,7 & 10 & 3,3 & 5 & 8 & 57 \\
\hline Tiempo de ciclo & 4 & 5,5 & 10 & 3,8 & 0 & 9 & 54 \\
\hline Cumplimiento de ventanas de tiempo & 0 & 5,4 & 10 & 3,5 & 0 & 8 & 58 \\
\hline Disponibilidad de vehículos & 3 & 5,3 & 10 & 3,7 & 0 & 8 & 50 \\
\hline Averías/extravíos & 0 & 5,3 & 10 & 3,6 & 2 & 8 & 46 \\
\hline Apariencia y limpieza de los vehículos & 2 & 4,8 & 10 & 4,0 & 0 & 8 & 48 \\
\hline Ruteo con menor distancia recorrida & 0 & 4,5 & 10 & 3,8 & 0 & 8 & 44 \\
\hline
\end{tabular}

Fuente: Elaboración propia.

Conforme a lo mostrado en la Tabla 7, de acuerdo con las notas dadas por los embarcadores a los operadores logísticos y transportadores, el criterio más relevante es el atendimiento de solicitudes urgentes. Esto se logra por la necesidad de los que retienen el producto final de contornar plazos y efectuar las entregas a los clientes cuando estas no están programadas. El embarcador tiene la necesidad de entrega de acuerdo con el contrato y los transportadores u operadores logísticos deben atender con esas demandas.

Se sabe que un indicador de desempeño de alto rigor cuando se evalúa a un proveedor de servicios es el cumplimiento de los acuerdos establecidos en contrato. Por lo tanto, con el fin de garantizar la entrega en la fecha acordada, los embarcadores indicaron como el segundo criterio más importante el cumplimiento de la agenda de entrega, como listado en la Tabla 7.

Las mejores prácticas en relación con el cumplimiento de la agenda de entrega permeabilizan valores entre el $95 \%$ y el $98 \%$ de todas recolecciones efectuadas dentro del plazo (Anaya, 2015). Al comparar la puntuación media dada en este criterio, existe una nota promedio de 6.2, es decir, una nota por debajo de lo deseado.

Se entiende que las calificaciones dadas a los dos criterios mencionados arriba tienen las notas más altas, debido a la necesidad y la importancia de que los prestadores de servicio se empreñen en cumplir con las expectativas del embarcador. 
En cuanto a los operadores logísticos, el orden de importancia de los criterios que se indicó otras prioridades, como se muestra en la Tabla 8.

Tabla 8 - Notas de los criterios evaluados y estadística descriptiva para operadores logísticos.

\begin{tabular}{|l|l|l|l|l|l|l|l|}
\hline Criterio & Mín. & \multicolumn{1}{|c|}{ Med. } & Máx. & $\begin{array}{c}\text { Desv. } \\
\text { Estand. }\end{array}$ & $\begin{array}{c}10 \\
\text { cuartil }\end{array}$ & $\begin{array}{c}\text { 30 } \\
\text { cuartil }\end{array}$ & $\begin{array}{c}\text { Notas encima } \\
\text { de la media }\end{array}$ \\
\hline Disponibilidad de vehículos & 4 & 7,3 & 10 & 3,4 & 7 & 9 & 54 \\
\hline $\begin{array}{l}\text { Atendimiento de solicitudes } \\
\text { en período de alta demanda }\end{array}$ & 2 & 7,0 & 10 & 3,4 & 6 & 9 & 58 \\
\hline $\begin{array}{l}\text { Cumplimiento de ventanas de } \\
\text { tiempo }\end{array}$ & 5 & 6,8 & 10 & 3,1 & 6 & 9 & 57 \\
\hline Entregas en la fecha acordada & 2 & 6,8 & 10 & 3,2 & 6 & 9 & 58 \\
\hline $\begin{array}{l}\text { Cumplimiento de agenda de } \\
\text { entrega }\end{array}$ & 2 & 6,7 & 10 & 3,3 & 5,8 & 9 & 57 \\
\hline Entregas sin error & 2 & 6,7 & 10 & 3,2 & 6 & 9 & 57 \\
\hline $\begin{array}{l}\text { Atendimiento de solicitudes } \\
\text { urgentes }\end{array}$ & 2 & 6,7 & 10 & 3,2 & 6 & 9 & 58 \\
\hline Tiempo de ciclo & 4 & 6,6 & 10 & 3,6 & 6 & 9 & 56 \\
\hline $\begin{array}{l}\text { Apariencia y limpieza de los } \\
\text { vehículos }\end{array}$ & 1 & 6,5 & 10 & 3,7 & 5 & 9 & 53 \\
\hline Robos & 0 & 6,3 & 10 & 3,9 & 2 & 8 & 48 \\
\hline Pedidos devueltos & 1 & 5,9 & 10 & 3,7 & 1,8 & 9 & 38 \\
\hline Averías/extravíos & 0 & 5,8 & 10 & 3,7 & 1,8 & 9 & 47 \\
\hline $\begin{array}{l}\text { Ruteo con menor distancia } \\
\text { recorrida }\end{array}$ & 0 & 5,4 & 10 & 4,1 & 0 & 9 & 46 \\
\hline
\end{tabular}

Fuente: Elaboración propia.

El indicador de desempeño más importante para los operadores logísticos es la disponibilidad de los vehículos, con una puntuación media de 7,3 y atendimiento de solicitudes en período de alta demanda con la puntuación media de 7,0. De la muestra obtenida, 79 cuestionarios, es decir, cerca del $70 \%$ atribuyeron notas encima de la media para los dos criterios. Por las cifras presentadas puede analizarse que, además de significativo, tener rutas disponibles y conseguir atender al cliente en periodos de alta demanda son criterios que forman parte de la estrategia de acción de operadores logísticos.

Cuando el operador logístico examina su relación con el embarcador, parece que la principal preocupación es cubrir las necesidades en cuanto a la cantidad de vehículos ideal, bien como atender 
los pedidos realizados en períodos de alta demanda.

Por último, la Tabla 9 muestra la evaluación de los transportadores.

Tabla 9 - Notas de los criterios evaluados y estadística descriptiva para transportadores.

\begin{tabular}{|l|l|l|l|l|l|l|l|}
\hline \multicolumn{1}{|c|}{ Criterio } & Mín. & Med. & Máx. & \multicolumn{1}{c|}{$\begin{array}{c}\text { Desv. } \\
\text { Estand. }\end{array}$} & $\begin{array}{c}10 \\
\text { cuartil }\end{array}$ & $\begin{array}{c}\text { 3o } \\
\text { cuartil }\end{array}$ & $\begin{array}{c}\text { Notas encima } \\
\text { de la media }\end{array}$ \\
\hline Atendimiento de solicitudes urgentes & 5 & 7,9 & 10 & 3,2 & 8 & 10 & 51 \\
\hline Cumplimiento de agenda de entrega & 6 & 7,6 & 10 & 3,2 & 8 & 9 & 51 \\
\hline Robos & 5 & 7,5 & 10 & 3,5 & 7 & 10 & 45 \\
\hline Entregas sin error & 2 & 7,5 & 10 & 3,1 & 7 & 9 & 47 \\
\hline Cumplimiento de ventanas de tiempo & 6 & 7,5 & 10 & 3,2 & 7 & 9 & 48 \\
\hline Entregas en la fecha acordada & 5 & 7,5 & 10 & 3,2 & 7 & 9 & 48 \\
\hline Pedidos devueltos & 1 & 7,3 & 10 & 3,5 & 7 & 9 & 45 \\
\hline Disponibilidad de vehículos & 6 & 7,3 & 10 & 3,5 & 7 & 9 & 47 \\
\hline $\begin{array}{l}\text { Atendimiento de solicitudes en período de } \\
\text { alta demanda }\end{array}$ & 6 & 7,3 & 10 & 3,3 & 7 & 9 & 46 \\
\hline Apariencia y limpieza de los vehículos & 6 & 7,2 & 10 & 3,6 & 8 & 9 & 49 \\
\hline Averías/extravíos & 2 & 7,1 & 10 & 3,3 & 6 & 9 & 43 \\
\hline Ruteo con menor distancia recorrida & 2 & 7.0 & 10 & 3,8 & 5 & 9 & 47 \\
\hline Tiempo de ciclo & 2 & 6,9 & 10 & 3,8 & 5 & 9 & 47 \\
\hline
\end{tabular}

Fuente: Elaboración propia.

Al evaluar a los transportadores, desde la perspectiva de los proveedores de servicios, los temas de mayor preocupación de garantía de la calidad son aquellos en los que los clientes, los operadores logísticos y los embarcadores también atribuyen las notas más altas, cerrando el ciclo de la demanda y la oferta de servicios. De esta forma, el atendimiento de solicitudes urgentes, con un promedio de 7.9 y el cumplimiento de la agenda acordada con promedio 7.6 son los indicadores más relevantes.

Se observa que los criterios más importantes, en función de la cantidad de notas por encima de la media, en la relación entre los miembros clave son los criterios relacionados con el nivel de servicio, la reputación en el mercado y la flexibilidad, por lo general representados por los criterios de atendimiento de solicitudes urgentes y en períodos de alta demanda, además de la entrega en la fecha acordada, alcanzando aproximadamente el 70\% de las notas.

Se considera que el cumplimiento de las ventanas de tiempo es un punto clave en el momento de evaluar al socio, siendo éste transportador u operador logístico. Una vez que no se cumple la ventana de tiempo, se producen cambios en las programaciones posteriores, tornando el ambiente de 
trabajo perjudicado y el compromiso de entrega dentro del plazo desfasado. En cuanto a la reputación en el mercado, se puede considerar que cuanto menor sea la ocurrencia de siniestros (averías, extravío o robo), mejor es la reputación de la empresa, lo que puede ser útil para mantener a los clientes embarcadores

Los altos niveles de exigencia entre la calidad de los servicios ofrecidos se da cuando hay mayor frecuencia de las reuniones de capacitación y visitas técnicas. Cuanto mayor es el contacto entre ambos lados de la prestación del servicio, mayor es la familiaridad entre los procesos de acondicionamiento, almacenamiento y transporte del producto, así como el conocimiento de las operaciones logísticas implícitas tales como el tiempo de permanencia en la plataforma de carga y descarga o la organización del almacén. Se supone entonces, que cuando las reuniones se llevan a cabo cada dos semanas o mensualmente hay un mayor conocimiento mutuo y problemas específicos se minimizan.

A partir de los datos proporcionados, alrededor del $40 \%$ de los encuestados respondieron que tienen una relación de más de cinco años con otros actores de la red de distribución, siendo que el $22,8 \%$ tienen de 3 a 5 años, el 21,1\% entre 1 y 3 años y sólo el 3,8\% tienen tiempo a la relación menos de 1 año. Se observó que cuanto mayor es la frecuencia de las reuniones de logística para alinear las expectativas y servicios, mayor es la relación de tiempo entre ellos. Estos resultados encuadran con las afirmaciones de Koçoğlu, İmamoğlu, İnce y Keskin (2011), quienes consideran que el intercambio de información es el medio de ventajas competitivas en la red de suministros y la forma más eficiente de crear vínculos al largo plazo. Los autores también creen que la integración de la cadena de suministro ha beneficiado el desempeño de la cadena de suministro, generando resultados similares en los indicadores de desempeño con mayores puntuaciones en lo referente a la contratación y la oferta de servicios.

Alrededor del $25 \%$ de las empresas en las que el tiempo de relación es mayor a 5 años, respondieron que hacen reuniones logísticas cada 15 días y el 50\% afirmó hacerlas mensualmente. Sin embargo, esta proporcionalidad no se encuadra tanto en el aspecto de entrenamiento, ya que éstos se proporcionan, en la mayoría de los casos, anualmente $(22,7 \%)$ o cada seis meses $(25,7 \%)$.

\section{Consideraciones finales}

Este artículo señala los principales indicadores de desempeño logístico que relacionan a los tres miembros de la red de suministro: embarcador, operador logístico y transportador y cómo se relacionan entre sí en sus procesos de oferta y demanda de servicios. 
Se identificó que la el atendimiento de solicitudes urgentes y el cumplimiento de la agenda de entrega son los indicadores de desempeño logístico mayor fuerza para los embarcadores y transportadores. En cuanto a los operadores logísticos, la disponibilidad de los vehículos y el atendimiento de pedidos en períodos de alta demanda son aquellos de mayor relevancia en la medición y control del desempeño dentro de la red logística. La identificación de los indicadores de desempeño logístico de mayor importancia tras reconocer un beneficio directo en el campo práctico, referente a la priorización de las inversiones a ser asignadas. En el caso específico de los transportadores, toda inversión hecha por éstos que posibilite una mejor atención a solicitudes urgentes y que mejore el cumplimiento de la agenda de entrega debe proporcionar mayor fidelización y por consecuencia, más servicios y aumento de ingresos. Para los profesionales involucrados con los operadores logísticos y con los embarcadores, los beneficios de conocer los indicadores más relevantes son igualmente importantes para direccionar inversiones y establecer políticas específicas de mejora.

Para el público académico, el levantamiento sistemático de los indicadores referentes a la distribución física entre quien oferta el producto y quien lo recibe permite efectuar comparaciones entre regiones, o entre tipos de mercancías y explorar las razones para diferenciación entre miembros clave similares. En el momento en que las relaciones a los pares son analizadas, se observa que para el operador logístico x embarcador, cuando se trata de la contratación de servicio, "atendimiento de solicitaciones urgentes" es la métrica más relevante. Por otro lado, al momento de ofertar el servicio "disponibilidad de vehículos" presenta una puntuación más alta.

En la relación entre embarcador x transportador, "atendimiento de solicitudes urgentes" también es más relevante en lo referente a contratación y oferta de servicio, siendo ese el criterio de menor dispersión entre las expectativas de los miembros.

Al tomar de referencia la relación operador logístico $x$ transportador, "disponibilidad de vehículos", también converge en los dos enfoques, tanto de oferta como de contratación de servicio, sin embargo "atendimiento de solicitudes urgentes" también es relevante en la muestra obtenida.

Como oportunidad de expansión de este estudio, la relación entre embarcador y operador logístico puede ser analizada más a fondo, ya que esta fue la relación de mayor variación en las puntuaciones y criterios evaluados. Identificar oportunidades de mejora en la relación entre ese eslabón de la cadena puede traer beneficios para ambos.

\section{Agradecimiento}

La investigación fue financiada por la Coordenação de Aperfeiçoamento de Pessoal de Nível Superior y Fundação de Ampara à Pesquisa de São Paulo - (fapesp) Proceso 2011/19271-9 . 


\section{Referencias}

Aguezzoul, A. (2014). Third-party logistics selection problem: A literature review on criteria and methods. Omega, 49, 69-78. doi:10.1016/j.omega.2014.05.009

Anaya, J. J. T. (2015). El Transporte de Mercancías: El Enfoque Logístico de la Distribución (2a Ed.). Madrid: ESIC EDITORIAL.

Angerhofer, B. J., \& Angelides, M. C. (2006). A model and a performance measurement system for collaborative supply chains. Decision Support Systems, 42(1), 283-301. doi:10.1016/j.dss.2004.12.005

Axsäter, S. (2015). Inventory Control (Tercera Ed.). Lund: Springer International Publishing. doi:10.1007/978-3-319-15729-0

Blesz, A. E. J., Sellitto, M. A., Ferreira, A. R., Herrmann, F. F., Sell, C. L., Ramos, P. V., \& Gruginskie, L. A. S. (2017). Inovação no mercado do transporte de cargas rodoviárias: Estudos de caso. Interciencia [en linea], 42(10), 692-697.

Conceição, S. V., \& Quintão, R. T. (2004). Avaliação do desenpenho logístico da cadeia brasileira de suprimentos de refrigerantes. Gestão \& Produção, 11(3), 441-453. doi:10.1590/S0104$530 \times 2004000300015$

Deshpande, A. (2012). Supply Chain Management Dimensions, Supply Chain Performance and Organizational Performance: An Integrated framework. International Journal of Business \& Management, 7(8), 2 - 19. doi:10.5539/ijbm.v7n8p2

Devaraj, S., Krajewski, L., \& Wei, J. C. (2007). Impact of eBusiness technologies on operational performance: The role of production information integration in the supply chain. Journal of Operations Management, 25(6), 1199-1216. doi:10.1016/j.jom.2007.01.002

Devlin, J., \& Yee, P. (2005). Trade Logistics in Developing Countries: The Case of the Middle East and North Africa. The World Economy, 28(3), 435-456. doi:10.1111/j.1467-9701.2005.00620.x

Domingues, M. L., Reis, V., \& Macário, R. (2015). A comprehensive framework for measuring performance in a third- party logistics provider. Transportation Research Procedia 10, 10(July), 662-672. doi:10.1016/j.trpro.2015.09.020

Gligor, D. M., \& Esmark, C. L. (2015). Supply chain friends: The good, the bad, and the ugly. Business Horizons, 58(5), 517-525. doi:10.1016/j.bushor.2015.05.005

Gunasekaran, A., Patel, C., \& McGaughey, R. E. (2004). A framework for supply chain performance measurement. International Journal of Production Economics, 87(3), 333-347. doi:10.1016/j.ijpe.2003.08.003

Jayaram, J., \& Tan, K. C. (2010). Supply chain integration with third-party logistics providers. International Journal of Production Economics, 125(2), 262-271. doi:10.1016/j.ijpe.2010.02.014

Kadłubek, M., \& Jereb, B. (2014). Measurement of the Logistic Customer Service Level in Commercial Cargo Motor Transport Companies, Logistics \& Sustainable Transport, 5(1), 8-15.

Koçoğlu, I.., İmamoğlu, S. Z., Ince, H., \& Keskin, H. (2011). The effect of supply chain integration on information sharing:Enhancing the supply chain performance. The Proceedings of 7 th International Strategic Management Conference, 24, 1630-1649. doi:10.1016/j.sbspro.2011.09.016

Liu, C.-L., \& Lyons, A. C. (2011). An analysis of third-party logistics performance and service provision. Transportation Research Part E: Logistics and Transportation Review, 47(4), 547-570. doi:10.1016/j.tre.2010.11.012

Martins, R. S., Xavier, W. S., De Souza Filho, O. V., \& Martins, G. S. (2011). Gestão do transporte orientada para os clientes: nivel de servico desejado e percebido. Revista de Administracao Contemporanea, 15(6), 1100-1119.

Meng, X. (2010). Assessment framework for construction supply chain relationships: Development and evaluation. International Journal of Project Management, 28(7), 695-707. doi:10.1016/j.ijproman.2009.12.006

Moura, V. D. M., \& Beuren, I. M. (2003). O suporte informacional da controladoria para o processo decisório da distribuição física de produtos. Revista Contabilidade \& Finanças, 14(31), 45-65. doi:10.1590/S1519-70772003000100004 
Murphy, P. R., \& Poist, R. F. (2000). Third-Party Logistics: Some User Versus Provider Perspectives. Journal of Business Logistics, 21(1), 121-133.

Nóbrega, A. P. G., \& Pizzolato, N. D. (2012). Aplicação do VMI para Melhoria de Indicadores de Desempenho Logístico. PUC - Rio. Retrieved from http://www.maxwell.vrac.pucrio.br/Busca_etds.php?strSecao=resultado\&nrSeq=21137@1

Prajogo, D., Chowdhury, M., Yeung, A. C. L., \& Cheng, T. C. E. (2012). The relationship between supplier management and firms operational performance: A multi-dimensional perspective. International Journal of Production Economics, 136(1), 123-130. doi:10.1016/j.ijpe.2011.09.022

Selviaridis, K., \& Spring, M. (2007). Third party logistics: a literature review and research agenda. The International Journal of Logistics Management, 18(1), 125-150. doi:10.1108/09574090710748207

Silva, L. F. de M., \& Pizzolato, N. D. (2012). O Impacto do Warehouse Management System (WMS) nos Indicadores de Desempenho Logístico: Aplicação em Centro de Distribuição de Medicamentos. PUCRio.

Tezuka, K. (2011). Rationale for utilizing 3PL in supply chain management: A shippers' economic perspective. IATSS Research, 35(1), 24-29. doi:10.1016/j.iatssr.2011.07.001

Tian, Y., Ellinger, A. E., \& Chen, H. (2010). Third-party logistics provider customer orientation and customer firm logistics improvement in China. International Journal of Physical Distribution \& Logistics Management, 40(5), 356-376. doi:http://dx.doi.org/10.1108/09600031011052822

Ülkü, M. A., \& Bookbinder, J. H. (2012). Optimal quoting of delivery time by a third party logistics provider: The impact of shipment consolidation and temporal pricing schemes. European Journal of Operational Research, 221(1), 110-117. doi:10.1016/j.ejor.2012.03.021

Yeung, K., Zhou, H., Yeung, A. C. L., \& Cheng, T. C. E. (2012). The impact of third-party logistics providers' capabilities on exporters' performance. International Journal of Production Economics, 135(2), 741-753. doi:10.1016/j.ijpe.2011.10.007

Yilmaz, O., \& Savasaneril, S. (2012). Collaboration among small shippers in a transportation market. European Journal of Operational Research, 218(2), 408-415. doi:10.1016/j.ejor.2011.11.018

Zhang, J., \& Tan, W. (2012). Research on the Performance Evaluation of Logistics Enterprise Based on the Analytic Hierarchy Process. Energy Procedia, 14, 1618-1623.

doi:10.1016/j.egypro.2011.12.1142

Recebido em: 07 mar. 2018 / Aprovado em: 14 set. 2018

Para referenciar este texto

Lazzarin, V., Silva, J. E. A. R., Ramos, M. F., \& Vieira, J. G. V. (2020). Redes de suministro: evaluación del desempeño logístico de los miembros clave en la distribución física de productos acabados. Exacta, 18(1), 74-100. https://doi.org/10.5585/Exacta.v18n1.8445. 